\title{
Determinant physical factors in the wheelchair tennis player
}

\author{
Alejandro Sánchez-Pay \\ Faculty of Sports Sciences. University of Murcia.
}

\begin{abstract}
The objective of this research was to identify the most determining physical factors in the ranking position of wheelchair tennis players (WT). In a national camp, the nine best nationally ranked Spanish male WT players $(38.35 \pm 11.28$ years, $63.77 \pm 7.01$ kg. weight) completed a test battery. Significantly higher correlations were observed in medicine ball throws, 5 and 20-metres sprints with racquet and in an agility test without racquet. In addition, the regression analysis identified two predictor models of the player's ranking position that included both the serve throw and the 5-metre racquet sprint. In conclusion, it is recommended that coaches and physical trainers include in their training programmes medicine ball exercises as well as acceleration drills over short distances.
\end{abstract}

Key words: tennis, performance, biomechanics, physical tests

Received: 23 January 2021

Acepted: 15 March 2021

Corresponding author: Alejandro Sánchez-Pay. Faculty of Sports Sciences. University of Murcia. Calle Argentina, 19, 30720 San Javier, Murcia, España. Email: aspay@um.es

\section{INTRODUCTION}

Wheelchair tennis (WT) has achieved the professionalization of the best players in the international ranking (Sánchez-Pay, 2019). This has been possible due to the fact that, in recent years, there has been an increase in the revenue through the prize money distributed in tournaments worldwide, as well as a growth in the companies interested in sponsoring players. No doubt that the presence of WT in the four Grand Slam has facilitated such professional growth. It is therefore vitally important for players to maintain the highest position possible in the ranking, although the information that identifies the most determinant variables for performance is still very scarce.

There are studies that show the differences between winners and losers based on match statistics (Sánchez-Pay, TorresLuque, Cabello Manrique, Sanz-Rivas, \& Palao, 2015), physiological parameters (Sindall et al., 2013), as well as speeds and distances during a match (Mason, van der Slikke, Hutchinson, \& Goosey-Tolfrey, 2020). However, there is no related information on the physical parameters of the athlete that better identify the ranking of the players. Therefore, the aim of this paper is to analyse the relationship of the fitness level of WT players and its relation with their position in the ranking.

\section{METHOD}

\section{Participants}

The sample consisted of the nine best male wheelchair tennis players in the Spanish national ranking $(38.35 \pm 11.28$ years, $63.77 \pm 7.01 \mathrm{~kg}$. weight). All of them played in the Open category and took part in national and international competitions. They were or had been among the top 150 in the international ranking.

\section{Procedure}

During a national camp, the players carried out a battery of tests distributed as follows: Day 1; Speed test (5, 10 and $20 \mathrm{~m}$.), agility test (T-test), service speed test, and medicine ball throw test (forehand, backhand and serve). Day 2: incremental resistance test (Hit and Turn Tennis Test) and manual dynamometry. All tests were conducted on an indoor hard court. The characteristics of each of the tests were:

- Displacement speed test: The time to travel a distance of 20 metres with doors located at 0,5, 10, and $20 \mathrm{~m}$. was measured. The players performed the test with and without a racquet three times each.

- Agility test (T-Test). The time to perform the agility test consisting of accelerations and decelerations, as well as turns for both sides, was measured. Each participant performed the test three times without a racquet, and three times with a racquet, with a $2 \mathrm{~min}$. rest time between each repetition.

- Service speed: The average service speed of 10 serves was measured and recorded using a radar gun. The radar was positioned behind the player at the same hitting height and oriented in the same direction as the ball.

- Medicine ball throw: Explosive force was evaluated through three $2 \mathrm{~kg}$ medicine ball throw tests, simulating forehand, backhand and serve shots. The players had to throw the ball simulating the technical gesture of the backhand and forehand (on each side with two hands) and the serve (with one hand from the loading position). 
- Manual dynamometry: The maximum isometric force in the flexors of the fingers was measured using a manual dynamometer. The best value of three attempts was recorded in $\mathrm{N} \cdot \mathrm{kg}-1$.

- Incremental resistance test (Hit and Turn Tennis Test): An adaptation of the test proposed by Ferrauti, Kinner, and Fernández-Fernández (2011) was carried out. The only difference was that the shots had to be performed on top of a cone located at the intersection of the singles line with the bottom line, coinciding with the sound signals emitted by a $C D$.

\section{Statistical analysis}

The Shapiro-Wilk and Levene tests were used to contrast the normality and homogeneity of variances for each variable. A Spearman correlation analysis was performed to identify those variables related to the ranking position. Subsequently, a stepwise linear regression analysis was performed to identify the parameters with the greatest influence on the ranking position. The significance was established at $\mathrm{p}<0.05$. All data were analysed with the IBM SPSS 25.0 statistical package for Macintosh (Armonk, NY: IBM Corp).

\section{RESULTS}

Table 1 shows the correlation coefficients of the different physical tests with the player ranking. The higher statistically correlation was observed in the medicine ball serve throw $(r=-0.995)$, showing a negative correlation. The 5 to 20 metre tests with racquet, and T-test without racquet showed the highest positive correlations $(r=0.817, r=0.833$ and $r=0.817$ respectively).

Table 1

Correlation coefficient of the physical tests with the ranking position.

\begin{tabular}{lcc}
\hline Test & $\mathrm{r}$ & $\mathrm{p}$ \\
\hline Dyna. Dom (kg) & -0.247 & 0.522 \\
Dyna. Non-Dom (kg) & -0.150 & 0.708 \\
Spe. Serve (km h -1) & -0.767 & 0.021 \\
5m without racquet (s) & 0.783 & 0.017 \\
10m without racquet (s) & 0.783 & 0.017 \\
20m without racquet (s) & 0.717 & 0.037 \\
5m with racquet (s) & 0.817 & 0.011 \\
10m with racquet (s) & 0.383 & 0.313 \\
20m with racquet (s) & 0.833 & 0.008 \\
T-Test without racquet (s) & 0.817 & 0.011 \\
T-Test with racquet (s) & 0.783 & 0.017 \\
Ball throw $\mathrm{F}(\mathrm{m})$ & -0.733 & 0.031 \\
Ball throw B (m) & $-0,700$ & 0.043 \\
Ball throw S (m) & -0.995 & $<0.001$ \\
Hit and Turn & -0.778 & 0.014 \\
\hline
\end{tabular}

Table 2 shows the results of the multiple regression analysis. The analysis mainly identified two models. The first model showed the medicine ball throw simulating a serve as the main predictive measure of the player's ranking $\left(r^{2}=0.830\right.$, $\mathrm{p}<0.001)$. The second model showed the medicine ball throw simulating a serve and the 5-metre sprint with the racquet as the two predictive variables in the player's ranking $\left(r^{2}=0.929, p<0.001\right)$.

Table 2

Multiple regression statistical analysis.

\begin{tabular}{lccccc}
\hline & $\mathrm{R}$ & $\mathrm{R}^{2}$ & $\mathrm{R}^{2}$ adjusted & $\mathrm{F}$ & Sig F. \\
& 0.911 & 0.830 & $\begin{array}{c}0.806 \\
\text { Beta }\end{array}$ & $\begin{array}{c}34.193 \\
\mathrm{~T}\end{array}$ & $\begin{array}{c}<0.001 \\
\text { Sig T. }\end{array}$ \\
Ball Throw S $(\mathrm{m})$ & & & -0.911 & -0.911 & $<0.001$ \\
\hline \multirow{2}{*}{ Model 2 } & $\mathrm{R}$ & $\mathrm{R}^{2}$ & $\mathrm{R}^{2}$ adjusted & $\mathrm{F}$ & Sig F. \\
& 0.964 & 0.929 & 0.905 & 39.239 & $<0.001$ \\
Ball Throw S $(\mathrm{m})$ & & & Beta & $\mathrm{T}$ & Sig T. \\
5m with racquet $(\mathrm{s})$ & & & -0.641 & -4.463 & 0.004 \\
\hline
\end{tabular}

The relationship between the medicine ball throwing tests simulating a serve and the 5 -metre sprint with a racquet is observed in Figures 1 and 2. The throw test maintains a negative relationship, since as the player's ranking moves away from the first place (greater numerical value), the distance of the throw decreases. On the contrary, in the 5-metre sprint the relationship is positive, since as the player's ranking is higher (lower numerical value), the time to cover the 5 metres decreases.

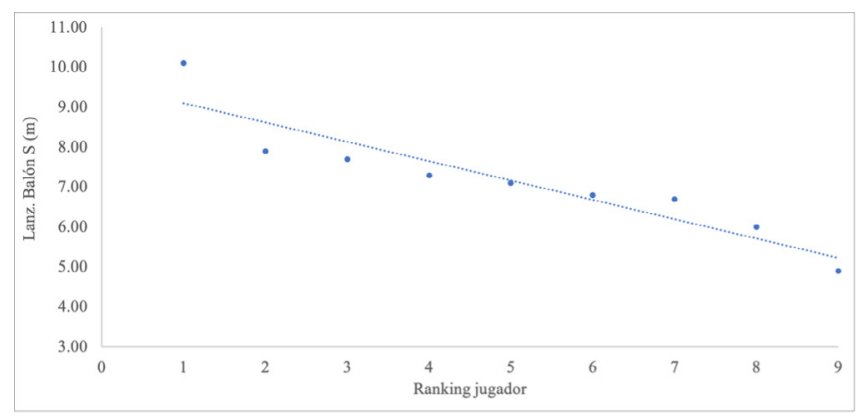

Figure 1. Relationship between the medicine ball throw test simulating a serve $(m)$ and the player's ranking. Figure 2. Relationship between the 5 -metre sprint with a racquet and the player's position in the ranking.

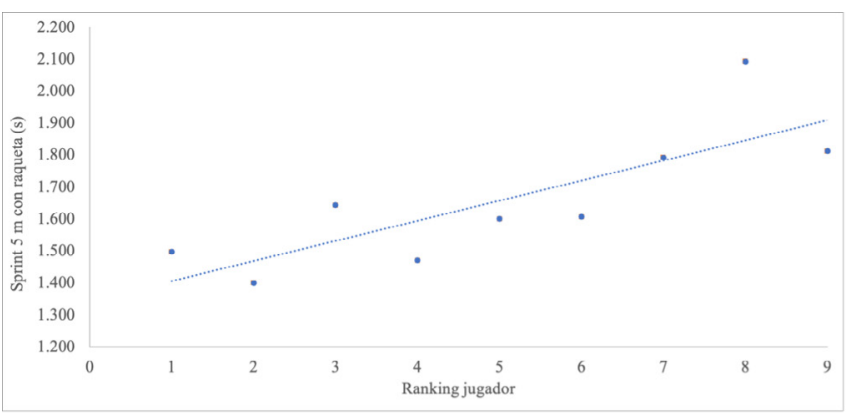

Figure 2. Relationship between the 5-metre sprint with a racquet and the player's position in the ranking. 


\section{DISCUSSION}

Knowing how physical demands relate to each other and identifying which are the variables that determine performance, can provide coaches with important and specific information for the design of exercises tailored to the needs of the sport. The objective of this research was to know the relationship of different physical demands evaluated through field tests with the ranking position of WT players. In general, it is observed that the vast majority of the measurements carried out showed a relationship with the ranking position of the players, although only the medicine ball throw simulating a serve and the 5-metre sprint with a racquet were shown as the predictive variables.

The medicine ball throw was shown as the main predictive measure of the player's ranking position (table 2). Given the similarity in the mechanics of throwing with the service technique, this test could have a direct relationship with service speed, which is known to be a good performance indicator in standing tennis (Brown \& O ' Donoghue, 2008) and is related to some parameters of the physical condition of tennis players (Fett, Ulbricht, \& Ferrauti, 2020). However, this is a hypothesis that needs to be tested in future studies.

The 5-metre racquet sprint was shown as a predictor variable of the player's ranking position (table 2). Therefore, a shorter acceleration time in the first 5 metres seems to be a good performance indicator. A good mobility in competitive WT is essential (Bullock \& Pluim, 2003), since it allows the player to hit more shots with success (Filipcic \& Filipcic, 2009). These movements are intermittent and multidirectional, which challenges the player to use specific movements such as accelerating, sprinting, braking, and turning the wheelchair (Roy, Menear, Schmid, Hunter, \& Malone, 2006; Sanz, 2003). The fact that the 5-metres sprint is shown as a predictor of performance, stresses the importance of accelerating versus achieving high speeds (Vanlandewijck, Theisen, \& Daly, 2001), where the propulsion most effective is when the maximum possible speed is achieved in the least number of pushes to the chair (Goosey-Tolfrey \& Moss, 2005).

\section{CONCLUSIONS}

The medicine ball toss simulating the serve, and the 5-metre sprint were shown as the variables that best predicted the ranking position of WT players. Therefore, coaches and physical trainers are encouraged to include the medicine ball throw as a transfer exercise to the technical gesture of serving within their training programmes. In the same way, a specific work of acceleration with the chair is necessary in the first metres, paying special attention to the individual biomechanics of the gesture, since the functional limitation of each athlete will determine to a greater or lesser extent the impulse technique on the chair hoops.

\section{REFERENCES}

Brown, E., \& O'Donoghue, P. (2008). Efecto del género y la superficie en la estrategia del tenis de élite. Coaching and Sport Science Review, 15(46), 11-13.

Bullock, M., \& Pluim, B. (2003). Wheelchair tennis and physical conditioning. ITF Wheelchair Tennis Coaches Review, 3(9), 2-10.

Ferrauti, A.; Kinner, V., y Fernandez-Fernandez, J. (2011). The hit \& turn tennis test: An acoustically controlled endurance test for tennis players. Journal of Sports Sciences, 29(5), 485-494. https://doi.org/b348px

Fett, J., Ulbricht, A., \& Ferrauti, A. (2020). Impact of physical performance and anthropometric characteristics on serve velocity in elite junior tennis players. Journal of Strength \& Conditioning Research, 34(1), 192-202. https://doi.org/10.1519/JSC.0000000000002641

Filipčič, T., \& Filipčič, A. (2009). Analysis of movement velocity and distance covered in wheelchair tennis. Kinesiologia Slovenica, 32, 25-32.

Goosey-Tolfrey, V. L., \& Moss, A. D. (2005). Wheelchair velocity of tennis players during propulsion with and without the use of racquets. Adapted Physical Activity Quarterly, 22, 291-301. https://doi.org/10.1123/apaq.22.3.291

Mason, B. S., van der Slikke, R. M. A., Hutchinson, M. J., \& Goosey-Tolfrey, V. L. (2020). Division, result and score margin alter the physical and technical performance of elite wheelchair tennis players. Journal of Sports Sciences, 1-8. https://doi.org/10.1080/02640414.2020.1737361

Roy, J. L. P., Menear, K. S., Schmid, M. M. a, Hunter, G. R., \& Malone, L. a. (2006). Physiological responses of skilled players during a competitive wheelchair tennis match. Journal of Strength and Conditioning Research / National Strength \& Conditioning Association, 20(3), 665-671. https://doi.org/10.1519/R-17845.1

Sánchez-Pay, A. (2019). Análisis de la producción científica sobre el tenis en silla de ruedas. Revista Iberoamericana de Ciencias de La Actividad Física y El Deporte. https://doi.org/10.24310/riccafd.2019.v8i2.6697

Sánchez-Pay, A Torres-Luque, G Cabello Manrique, D, Sanz-Rivas, D, \& Palao, J. M. (2015). Match analysis of women's wheelchair tennis matches for the Paralympic Games. International Journal of Performance Analysis in Sport, 15(1), 69-79. https://doi.org/10.1080/24748668.2015.11868777

Sanz, D. (2003). Wheelchair tennis. Barcelona: Paidotribo.

Sindall, P., Lenton, J. P., Tolfrey, K., Cooper, R. a, Oyster, M., \& Goosey-Tolfrey, V. L. (2013). Wheelchair tennis match-play demands: effect of player rank and result. International Journal of Sports Physiology and Performance, 8(1), 28-37. https://doi.org/10.1123/ijspp.8.1.28

Vanlandewijck, Y., Theisen, D., \& Daly, D. (2001). Wheelchair propulsion biomechanics: implications for wheelchair sports. Sports Medicine, 31(5), 339-367. https://doi.org/10.2165/00007256-200131050-00005

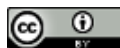

This text is under a Creative Commons BY 4.0 license

You are free to Share - copy and redistribute the material in any medium or format - and Adapt the content - remix, transform, and build upon the material for any purpose, even commercially under the following terms:

Attribution: You must give appropriate credit, provide a link to the license, and indicate if changes were made. You may do so in any reasonable manner, but not in any way that suggests the licensor endorses you or your use. 